\title{
EFECTO SIMBIÓTICO DEL EXTRACTO DE Smallanthus sonchifolius (YACÓN) Y Lactobacillus plantarum FRENTE A Escherichia coli
}

\author{
Symbiotic relationship from yacon extract (Smallanthus sonchifolius) and Lactobacillus \\ plantarum against Escherichia coli
}

Carlos A. Vegas, Boris O. Pichihua, Carmen Peña, Amparo I. Zavaleta

Laboratorio de Biología Molecular, Facultad de Farmacia y Bioquímica, Universidad Nacional Mayor de San Marcos

\section{RESUMEN}

El desarrollo de estrategias que permitan un mayor control de la microbiota intestinal ha incrementado el interés por asociar prebióticos y probióticos, en una relación simbiótica, con el propósito de reducir la presencia de microorganismos patógenos. El objetivo de este estudio fue analizar el efecto simbiótico del extracto de Smallanthus sonchifolius (yacón) y Lactobacillus plantarum sobre el crecimiento de Escherichia coli enteropatógena. Para ello, previamente se analizó la concentración óptima del extracto de yacón para el crecimiento de L. plantarum y su efecto prebiótico. La cinética de crecimiento de ambos microorganismos fue determinada por densidad óptica, conteo por microscopio y células viables en placas. Lactobacillus plantarum presentó un óptimo crecimiento a $15^{\circ}$ Brix, alcanzando $10^{9}$ células $/ \mathrm{mL}$; por el contrario, E. coli se mantuvo a bajos niveles poblacionales. La combinación de extracto de yacón y L. plantarum inhibió el crecimiento de $E$. coli enteropatógena a las 16 h de incubación.

Palabras clave: Prebiótico, probiótico, Smallanthus sonchifolius, Lactobacillus plantarum, Escherichia coli.

\section{SUMMARY}

The development of strategies for a better control of gut microbiota have increased the interest in associate prebiotics and probiotics, in a symbiotic state, in order to reduce the presence of pathogenic microorganisms. The aim of this work was to study the symbiotic effect between Smallanthus sonchifolius (yacon) extract and Lactobacillus plantarum against the growth of enteropathogenic Escherichia coli. To do this, the best concentration of yacon extract for the growth of $L$. plantarum and their prebiotic effect were previously done. The microbial growth kinetic was determined by optical density, counting by microscope and viability in plate. L. plantarum presented an optimal growth at $15^{\circ} \mathrm{Brix}$, reaching $10^{9} \mathrm{cells} / \mathrm{mL}$; whereas $E$. coli remained at low population levels. The combination of yacon extract and L. plantarum totally inhibited the growth of enteropathogenic E. coli at $16 \mathrm{~h}$ of incubation.

Keywords: Prebiotic, probiotic, Smallanthus sonchifolius, Lactobacillus plantarum, Escherichia coli.

\section{INTRODUCCIÓN}

$\mathrm{E}$ n los últimos años, a nivel mundial se ha incrementado la búsqueda de estrategias que permitan manipular la microbiota presenteen el intestinogrueso humano, con el propósito de favorecer el crecimiento de microorganismos con efectos beneficiosos para la salud, reduciendo el riesgo a contraer enfermedades por la presencia de microorganismos patógenos ${ }^{(1)}$. En consecuencia, se ha propuesto el consumo de prebióticos, probióticos y su combinación (simbióticos).

El prebiótico es un ingrediente alimenticio no digerible que estimula selectivamente el crecimiento y actividad de un grupo limitado de bacterias en el colón (2). Los ingredientes, utilizados como prebióticos son los galactooligosacáridos (GOS) y fructooligosacáridos (FOS) ${ }^{(3)}$. El yacón (Smallanthus sonchifolius), es una raíz andina especialmente conocida por su alto contenido de FOS ${ }^{(4)}$, por lo que ha sido recomendado como alimento funcional e ingrediente de suplementos dietéticos con potencial prebiótico.

El probiótico se define como un ingrediente microbiano vivo, que al ser ingerido en cantidades suficientes, influye positivamente en la salud de quien lo consume ${ }^{(5)}$. Las bacterias probióticas comunes, que están mayoritariamente en el tracto intestinal, pertenecen a los géneros Bifidobacterium y Lactobacillus $^{\left({ }^{6}\right)}$. Estas bacterias producen compuestos como ácidos orgánicos y bacteriocinas que inhiben el crecimiento de microorganismos patógenos ${ }^{(7)}$.

En los últimos años, la mezcla de prebióticos y probióticos en una relación simbiótica, ha sido propuesta como una alternativa para aumentar la supervivencia de los probióticos en el tracto intestinal. En este estado, 
se produce un efecto sinérgico ya que los prebióticos constituyen el sustrato principal de las bacterias probióticas, estimulan el crecimiento decepas específicas, y por tanto, contribuyen a la selección y colonización de la microbiota responsable de favorecer la salud ${ }^{(2,8)}$.

El efecto prebiótico del yacón ha sido demostrado en bacterias lácticas pertenecientes al género Bifidobacterium y Lactobacillus ${ }^{(9)}$. Sin embargo, el efecto simbiótico del yacón con las bacterias lácticas, aún no ha sido estudiado. En consecuencia, el objetivo de este estudio fue evaluar el efecto simbiótico del extracto de yacón y Lactobacillus plantarum sobre el crecimiento de Escherichia coli enteropatogena. Para ello, previamente se optimizaron las concentraciones de extracto de yacón para el buen crecimiento de $L$. plantarum y se analizó el efecto prebiótico del extracto en ambos microorganismos.

\section{MATERIALES Y MÉTODOS}

\section{Elaboración del extracto de yacón}

Las raíces de yacón utilizadas para este estudio proceden del distrito de Palca, provincia de Tarma (Junín), ubicado a $3050 \mathrm{~m}$ de altitud. El procedimiento utilizado para la obtención del extracto ha sido descrito por Manrique et al. ${ }^{(10)}$, diferenciándose únicamente en que la concentración del jugo prebiótico se realizó a $90^{\circ} \mathrm{C}$ con agitación hasta obtener $40^{\circ}$ Brix. Finalmente, antes de llevar a cabo el estudio microbiológico, el extracto fue centrifugado a $5000 \mathrm{rpm}$, por 20 minutos, y el sobrenadante autoclavado a $115^{\circ} \mathrm{C}$ por 15 minutos.

\section{Microorganismos, medios de cultivo condiciones de incubación}

Los microorganismos utilizados fueron Lactobacillus plantarum CECT 748 y Escherichia coli enteropatógena.

L. plantarum fue reactivado en el caldo de cultivo De Mann, Rogosa y Sharpe (MRS; Merck KGaA, Darmstadt, Alemania) y E. coli en caldo de cultivo Triptona de soya (TSB; Oxoid Ltd., Basingstoke, Hampshire, Inglaterra). Los medios de cultivo sólidos empleados para $L$. plantarum y $E$. coli fueron agar MRS suplementado con $2 \%(\mathrm{p} / \mathrm{v})$ de agar y agar MacConkey (Merck KGaA, Darmstadt, Alemania), respectivamente. Los cultivos bacterianos fueron incubados a $37^{\circ} \mathrm{C}$ por $24 \mathrm{~h}$ en condiciones de aerobiosis.

\section{Estudio de los efectos prebiótico y simbiótico}

Los efectos prebiótico y simbiótico fueron evaluados mediante el análisis de las cinéticas de crecimiento de $L$. plantarum y $E$. coli cultivados en matraces Erlenmeyer de $250 \mathrm{~mL}$, por triplicado. Todos los cultivos se realizaron a un volumen final de 25 $\mathrm{mL}$, de forma estática, fueron incubados a $37^{\circ} \mathrm{C}$ y en condiciones de aerobiosis. Los puntos de muestreo fueron a $0,4,16,24,48$ y $72 \mathrm{~h}$. El seguimiento de los cultivos fue realizado mediante la medición de la densidad óptica por espectrofotometría a $600 \mathrm{jm}$ (Génesis $10 \mathrm{uv}$, Thermo Electron Corporation. USA), el contaje de la población de microorganismos por microscopía mediante cámara de Neubauer mejorada (o,0025 $\mathrm{mm}^{2}$ y $0,100 \mathrm{~mm}$ de profundidad) y el recuento de viables en agares MRS y MacConkey para L. plantarum y E. coli, respectivamente. Asimismo, se realizaron análisis físico-químicos al inicio y final del periodo de incubación, tales como: determinación de la acidez total titulable ${ }^{(11)}, \mathrm{pH}$ mediante potenciómetro 213 (Hanna Instruments SL, España) y sólidos solubles totales ( ${ }^{\circ}$ Brix) mediante refractómetro manual RHB32 ATC (Lumen Optical Instrument Co., Ltd., China).

Previamente, se determinó el crecimiento óptimo de $L$. plantarum, para lo cual, se inóculo a diferentes concentraciones de extracto de yacón: 1, 5, 10, 15, 20, 25 y $30{ }^{\circ}$ Brix, suplementado con los componentes del caldo MRS sin glucosa. La población inicial de $L$. plantarum fue de $1 \mathrm{X}^{6} \mathrm{O}^{6} \mathrm{cél} / \mathrm{mL}$. El seguimiento de los cultivos se realizó por densidad óptica.

\section{Efecto prebiótico}

La población inicial de ambos microorganismos fue de $1 \times 10^{6}$ cél $/ \mathrm{mL}$. Los resultados microbiológicos se compararon con los obtenidos en caldos MRS para $L$. plantarum y TSB para E. coli.

\section{Efecto simbiótico}

Paraelanálisis, losmicroorganismosfueroninoculados conjuntamente a la concentración de $1 \times 10^{7} \mathrm{cé} / \mathrm{mL}$.

\section{RESULTADOS}

Determinación de la concentración del extracto de yacón para el crecimiento de $L$. plantarum

Para conseguir un buen crecimiento de $L$. plantarum se analizaron diferentes concentraciones del extracto de yacón expresadas en ${ }^{\circ}$ Brix.

En la figura 1, se observa un mayor crecimiento a 5, 10 y $15^{\circ}$ Brix; seleccionándose la última concentración, ya que la velocidad de crecimiento fue ligeramente superior a las otras dos concentraciones. 
Efecto prebiótico del yacón sobre el crecimiento de $L$. plantarum

La cinética de crecimiento de L. plantarum obtenida de los cultivos con extracto de yacón a 15 ${ }^{\circ}$ Brix, fue comparada con la obtenida en caldo MRS (control). El análisis por densidad óptica, mostró que $L$. plantarum creció mejor en medio MRS que en el extracto de yacón. Sin embargo, en el contaje por microscopía óptica se observó lo contrario (figura 2). Resultados similares al microscopio fueron obtenidos en el recuento de viables. Con el extracto de yacón se consiguieron poblaciones mayores a $10^{9} \mathrm{UFC} / \mathrm{mL}$; mientras que en el medio MRS fue $10^{8} \mathrm{UFC} / \mathrm{mL}$. La población viable de $L$. plantarum en caldo con extracto de yacón disminuyó a las $24 \mathrm{~h}$, mientras que en caldo MRS a las $48 \mathrm{~h}$. Al finalizar el tiempo de incubación, el análisis físico-químico mostró que $L$. plantarum incrementó la acidez total de $0,45 \%(\mathrm{p} / \mathrm{v})$ a $1,85 \pm$ $0,173 \%(\mathrm{p} / \mathrm{v})$, disminuyendo el $\mathrm{pH}$ de 5,85 a 3,79 \pm o,o12 (tabla 1). Asimismo, la concentración de sólidos solubles totales aumentó de 15 a 15,72 \pm 0,289 ${ }^{\circ}$ Brix.

\section{Efecto prebiótico del yacón sobre el crecimiento de $E$. coli}

La cinética de crecimiento de $E$. coli obtenida de los medios con extracto de yacón, fue comparada con la obtenida en caldo TSB (control). En los tres análisis microbiológicos realizados se observó que el extracto de yacón no es un medio adecuado para el crecimiento de $E$. coli (figura 2). Tanto en la densidad óptica, en el conteo por microscopia óptica, como en el recuento de viables, se observó que desde la inoculación $E$. coli se mantuvo a bajos niveles poblacionales. Asimismo, en el recuento de viables se observó que la población de $E$. coli disminuyó a partir de las $16 \mathrm{~h}$. El análisis físico-químico realizado al inicio y final del periodo de incubación no mostró una variación significativa (tabla 1).

\section{Efecto simbiótico del yacón con L. plantarum sobre el crecimiento de $E$. coli}

Previo al análisis del efecto simbiótico, se realizaron pruebas de cultivabilidad de L. plantarum y E. coli en placas conteniendo medio MRS y MacConkey, y viceversa, comprobándose que los medios son específicos; por lo tanto, las colonias recuperadas de ellos correspondieron a $L$. plantarum y $E$. coli, respectivamente.

En relación al efecto simbiótico, tanto la recuperación de colonias de $L$. plantarum en medio MRS, como la población total observada al microscopio fueron $10^{9}$ cél $/ \mathrm{mL}$ (figura 3). Sin embargo, la población de $L$. plantarum en medio MRS disminuyó a partir de las 24 h; mientras que E. coli a partir de las 16 h.

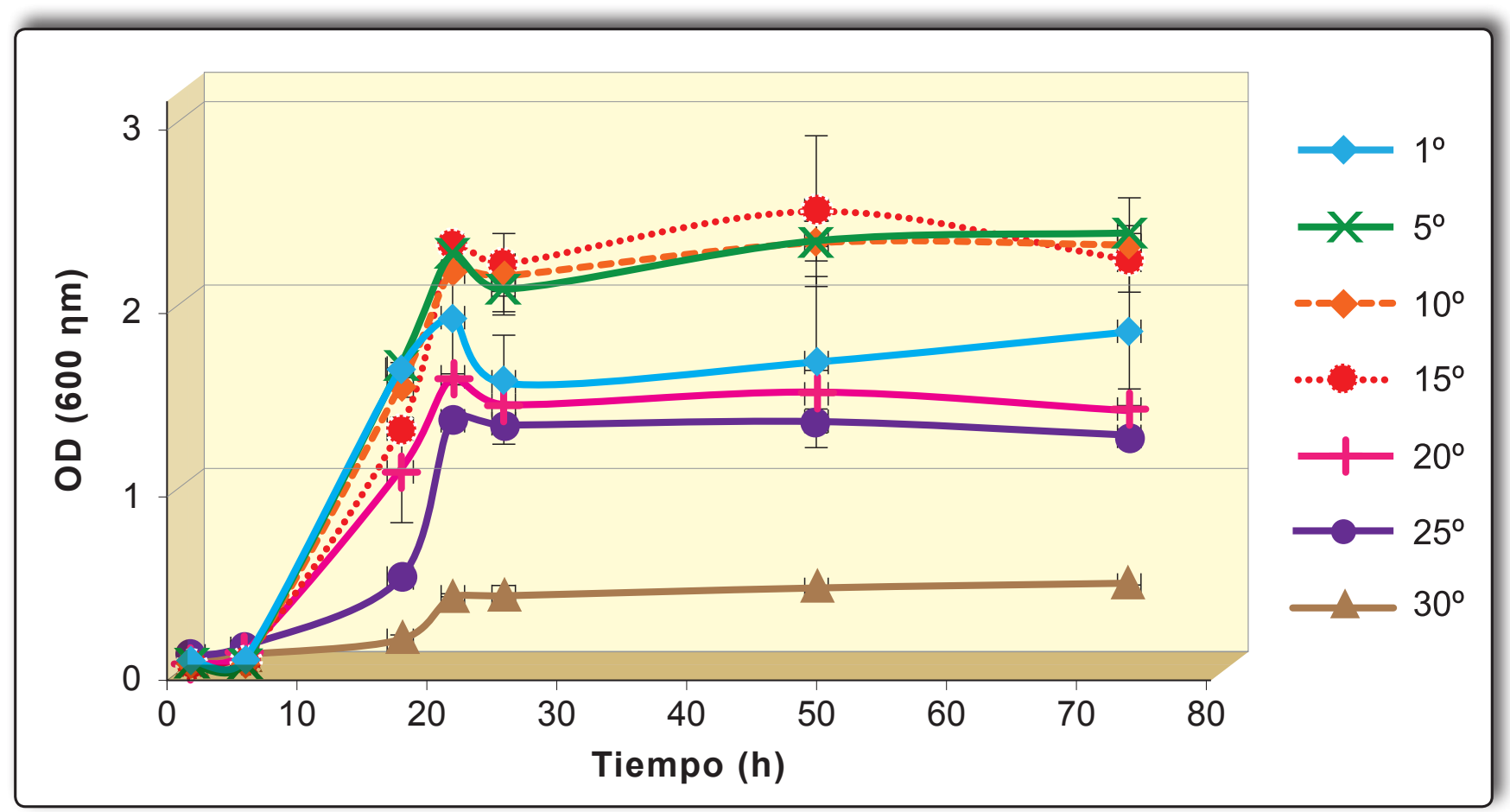

Figura 1. Cinética de crecimiento de L. plantarum a diferentes concentraciones de extracto de yacón en ${ }^{\circ}$ Brix. 


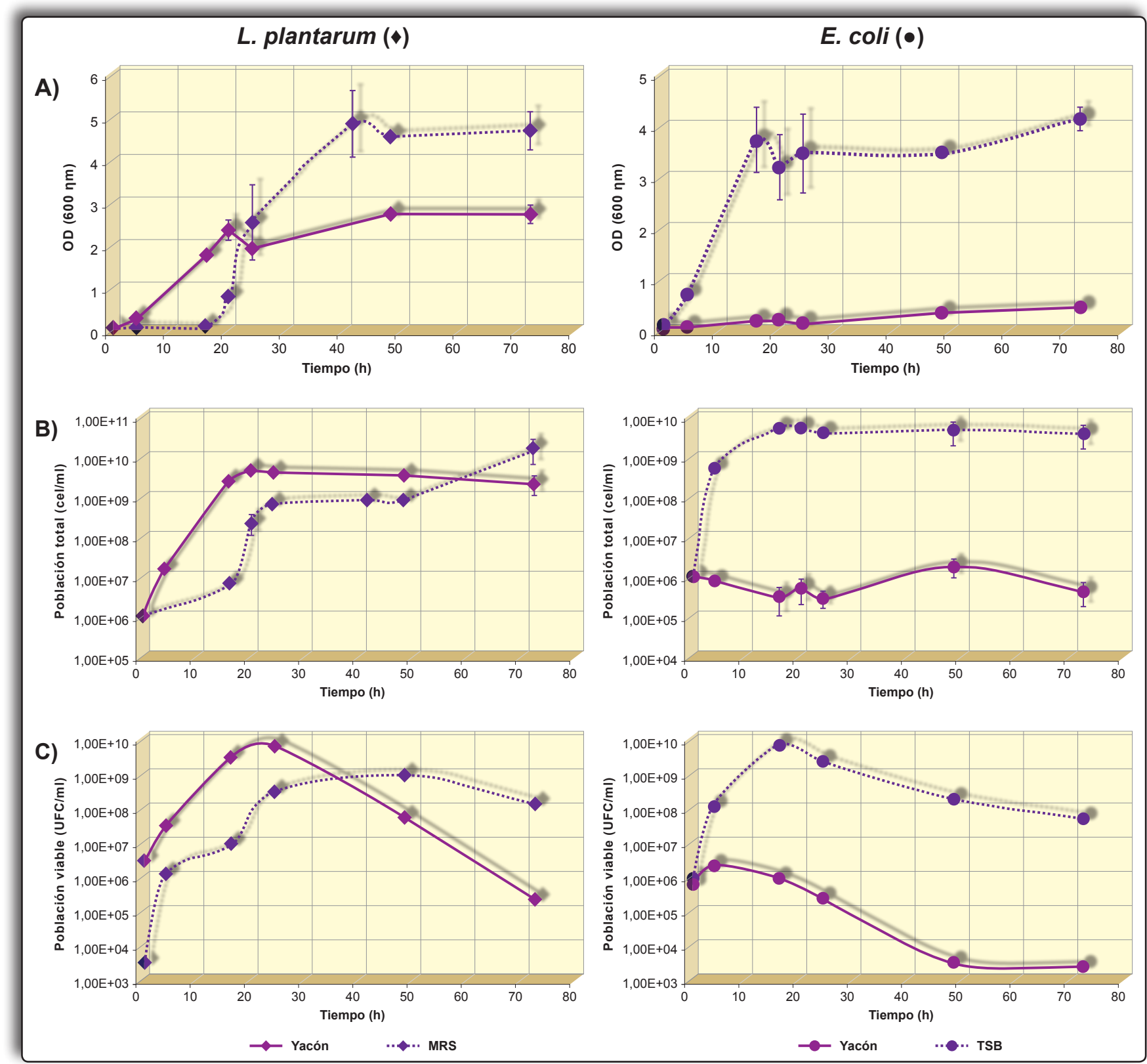

Figura 2. Cinética de crecimiento de L. plantarum y E. coli en medios conteniendo extracto de yacón, MRS y TSB. A) Densidad óptica a 600 ๆm. B] Conteo al microscopio de la población total. C) Recuento de viables en placa.

Al finalizar el periodo de incubación, la acidez total se incrementó de $0,45 \%(\mathrm{p} / \mathrm{v})$ a $1,8 \pm 0,173 \%$ $(\mathrm{p} / \mathrm{v})$; el $\mathrm{pH}$ disminuyó de 5,85 a 3,85 \pm o,017 y la concentración de sólidos solubles se mantuvo en $15 \pm$ $0,2{ }^{\circ} \operatorname{Brix}($ tabla 1$)$.

\section{DISCUSIÓN}

Se evaluó el efecto simbiótico de la combinación de L. plantarumy extracto deyacón sobre el crecimiento de $E$. coli enteropatógena, para lo cual, previamente se determinó la adecuada concentración del extracto de yacón para el óptimo crecimiento de L. plantarum, ya que una baja o alta concentración podría afectar su crecimiento y, en consecuencia, reducir o inactivar los efectos beneficiosos en la salud. Así, en extracto de yacón a la concentración de $15^{\circ}$ Brix se obtuvo mayor población de $L$. plantarum que en medio MRS; este incremento se explica por la capacidad de fermentar FOS ${ }^{(9)}$. Por el contrario, el extracto de yacón mostró ser un medio inadecuado para el cultivo de E. coli, ya que la población inoculada se mantuvo hasta las 




Figura 3. Efecto simbiótico del extracto de yacón y L. plantarum sobre el crecimiento de E. coli.

$16 \mathrm{~h}$, posiblemente debido a los azúcares residuales presentes en el extracto, al agotarse estos compuestos, la población de $E$. coli disminuyó drásticamente.

Los mecanismos de cómo los oligosacáridos prebióticos son selectivamente metabolizados por miembros beneficiosos de la microbiota intestinal, no están adecuadamente entendidos ${ }^{(12)}$. Sin embargo los estudios continúan; así por ejemplo, se ha descrito que la celobiosa estimula el crecimiento de Lactobacillus rhamnosus y Streptoccocus thermophilus y mantiene bajas poblaciones de E. coli y Staphyloccus aureus ${ }^{(1)}$.

Una vez analizado el efecto prebiótico del extracto de yacón en L. plantarumy $E$. coli, se procedió a analizar el efecto simbiótico del extracto y $L$. plantarum sobre el crecimiento de $E$. coli. Los resultados mostraron que la población obtenida por el conteo al microscopio a las $16 \mathrm{~h}$ correspondería a L. plantarum, basándonos en la población viable obtenida en medio MRS y en la ausencia de colonias de $E$. colien medio MacConkey. La inhibición del crecimiento de $E$. colipor la combinación del extracto de yacón y L. plantarum, coincide con otros estudios realizados, donde especies del género Lactobacillus inhiben el crecimiento de cepas de $E$. coli gastroentéricas ${ }^{(13,14)}$. El incremento de la acidez por L. plantarum, y en consecuencia, la disminución del $\mathrm{pH}$ del medio pueden estar relacionadas con esta inhibición. Se ha descrito que la producción de ácidos orgánicos por las bacterias lácticas no sólo disminuye el $\mathrm{pH}$, sino también afectan el crecimiento de patógenos $(15,16)$. Además, las bacterias ácido lácticas producen bacteriocinas como agentes antimicrobianos ${ }^{(17)}$; así, cepas de $L$. plantarum producen plantaricina con efecto contra $E$. coli ${ }^{(18)}$.

Esta investigación permite demostrar el efecto simbiótico del yacón y $L$. plantarum sobre el crecimiento de $E$. coli enteropátogena. Sin embargo, es necesario ampliar el estudio para determinar el espectro antimicrobiano, la dosis óptima y la forma farmacéutica.

\section{CONCLUSIONES}

El extracto de yacón, como fuente natural de prebióticos, estimuló el crecimiento de $L$. plantarum y, por el contrario, mantuvo el crecimiento de $E$. coli enteropatógena a bajos niveles poblacionales. La mezcla del extracto de yacón y $L$. plantarum inhibió el crecimiento de $E$. coli enteropatógena.

Agradecimientos. Este trabajo fue financiado

Tabla 1. Análisis físico-químico del efecto prebiótico y simbiótico.

\begin{tabular}{|c|c|c|c|c|c|c|}
\hline \multirow{3}{*}{$\begin{array}{l}\text { Efecto prebiótico y } \\
\text { simbiótico }\end{array}$} & \multicolumn{2}{|c|}{$\begin{array}{c}\text { Sólidos solubles totales } \\
\left.\text { ( }{ }^{\circ} \mathrm{Brix}\right)\end{array}$} & \multicolumn{2}{|c|}{$\begin{array}{l}\text { Acidez total titulable } \\
\qquad \%, p / v)\end{array}$} & \multicolumn{2}{|c|}{ pH } \\
\hline & \multicolumn{6}{|c|}{ Tiempo (h) } \\
\hline & 0 & 72 & $\mathbf{0}$ & 72 & $\mathbf{0}$ & 72 \\
\hline \multicolumn{7}{|l|}{ Prebiótico: } \\
\hline yacón vs $E$. coli & \multirow{2}{*}{15} & 15 & \multirow{2}{*}{0,45} & 0,45 & \multirow{2}{*}{5,85} & $5,72 \pm 0,006$ \\
\hline $\begin{array}{l}\text { Simbiótico: } \\
\text { (yacón }+L \text {. plantarum vs } E \text {. coli) }\end{array}$ & & $15 \pm 0,2$ & & $1,8 \pm 0,173$ & & $3,85 \pm 0,017$ \\
\hline
\end{tabular}


con fondos del Consejo Nacional de Ciencia, Tecnología e Innovación Tecnológica, contrato № o15-2013-CONCYTEC-P y Fondos para la Innovación, CienciayTecnología, Contrato № 230-FINCYT-IA-2013.

\section{REFERENCIAS BIBLIOGRÁFICAS}

1. Yacine A, Aïcha TM, Belkacem M, Khadidja EK, Bochra M, Souhila K. The in vitro effect of a symbiotic combination between cellobiose and two probiotic strains toward two pathogenic bacteria. J Life Sci 2012; 6(6): 615-23.

2. Gibson GR, Roberfroid, MB. Dietary modulation of the human colonic microbiota: Introducing the concept of prebiotics. Journal of Nutrition 1995; 125(6): 1401-12.

3. Voragen GJA. Technological aspects of functional foodrelated carbohydrates. Trends Food Sci Tech 1998; 9(8-9): 328-35.

4. Campos D, Betalleluz-Pallardel I, Chirinos R, AguilarGalvez A, Noratto G, Pedreschi R. Prebiotic effects of yacon (Smallanthus sonchifolius Poepp. \& Endl), a source of fructooligosaccharides and phenolic compounds with antioxidant activity. Food Chem 2012; 135(3): 1592-9.

5. Ashwell M. Conceptos sobre alimentos funcionales. ILSI Europe Concise Monograph Series, ILSI Press. 2005.

6. ONU/FAO. Probióticos en los alimentos. Propiedades saludables y nutricionales y directrices para la evaluación. Estudio FAO Alimentación y nutrición 85 . Organización de las Naciones Unidas para la Agricultura y la Alimentación. Roma, 2006

7. Pundir RK, Rana S, Kashyap N, Kaur A. Probiotic potential of lactic acid bacteria isolated from food samples: an in vitro study. J Appl Pharm Sci 2013; 3(3): 85-93.

8. Roberfroid MB. Prebiotics and probiotics: are they functional foods?. Am J Clin Nutr 2000; 71(suppl.): 1682S-7S.

9. Pedreschi R, Campos D, Noratto G, Chirinos R, CisnerosZevallos L. Andean yacon root (Smallanthus sonchifolius Poepp. Endl) fructooligosaccharides as a potential novel source of prebiotics. J Agr Food Chem 2003; 51(18): 5278- 84 .

10. Manrique I, Párraga A, Hermann M. Jarabe de yacón. Principios y Procesamiento. Serie: Conservación y uso de la biodiversidad de raíces y tubérculos andinos: Una década de investigación para el desarrollo (1993-2003). № 8A. Centro Internacional de la Papa, Universidad Nacional Daniel Alcides Carrión. Fundación Erbacher, Agencia Suiza para el Desarrollo y la Cooperación. Lima, 2005. p. 31.

11. Ough CS, Amerine MA. Methods for analysis of must and wines. Wiley-Interscience. California, 1987.

12. Perrin S, Warchol J, Grill JP, Schneider F. Fermentation of fructooligosaccharides and their components by Bifidobacterium infantis ATCC 15697 on batch culture in semi-synthetic medium. J Appl Microbiol 2001; 90(6): 859-65.

13. Piper EL, Leyva KJ. Growth inhibition of gastrointestinal strains of Escherichia coli by Lactobacillus species. J ArizNev Acad Sci 2009; 41(2): 49-54.

14. Fooks JL, Gibson GR. In vitro investigations of the effect of probiotics and prebiotics on selected human intestinal pathogens. FEMS Microbiol Ecol 2002; 39(1): 67-75.

15. Tambekar DH, Bhutada SA. Studies on antimicrobial activity and characteristics of bacteriocins produced by Lactobacillus strains isolated from milk of domestic animals. Internet J Microbiol 20o9; 8(2): 1-6.

16. 16. Matamoros S, Pilet MF, Gigout F, Prévost $H$, Leroi F. Selection and evaluation of seafood-borne psychrotrophic lactic acid bacteria as inhibitors of pathogenic and spoilage bacteria. Food Microbiol 2009; 26(6): 638-44.

17. Ahmed Z, Wang Y, Cheng Q, Imran M. Lactobacillus acidophilus bacteriocin, from production to their application: An overview. African J Biotech 2010; 9(20): 2843-50.

18. Jama YH, Varadaraj MC. Antibacterial effect of plantaricin LP84 on foodborne pathogenic bacteria occurring as contaminants during idli batter fermentation. World J Microbiol Biotech 1999; 15(1): 27-32.

\section{Correspondencia}

$\begin{array}{ll}\text { Nombre: } & \text { Carlos Alfredo Vegas Pérez } \\ \text { Dirección: } & \text { Jr. Puno 1002, Lima 1 } \\ \text { E-mail: } & \text { azavaletap@unmsm.edu.pe }\end{array}$

